\title{
Ethical Aspects of Breast Cancer Treatment
}

\author{
Ehsan Shamsi Gooshki ${ }^{1,2, *}$ \\ ${ }^{1}$ Medical Ethics and History of Medicine Research Center, Tehran University of \\ Medical Sciences, Tehran, Iran \\ ${ }^{2}$ Breast Cancer Research Center, ACECR, Tehran, Iran \\ ${ }^{*}$ Corresponding author: Ehsan Shamsi Gooshki, Breast Cancer Research Center, ACE- \\ CR, Tehran, Iran.E-mail: Ehsanshamsi713@gmail.com
}

DOI: $10.21859 / \mathrm{mci}-01016$

Submitted: 20 June 2016

Revised: 15 July 2016

Accepted: 29 July 2016

ePublished: 08 September 2016

\section{Keywords:}

Ethics

Breast Neoplasms

Therapeutics

(C) 2016. Multidisciplinary Cancer Investigation

\section{Dear Editor}

According to a universal consensus and agreement, all diagnostic, curative and rehabilitative medical intervention and biomedical research on patients as human participants, including those related to breast disease and breast cancer, must be performed in a morally acceptable manner. In other words, a medical decision would be "right" if it is ethically justifiable. Similar to diagnosis and treatment of other diseases, people with breast problems such as breast cancer require medical and anthropological evaluations on one hand and ethical-legal analysis, on the other hand. It is important to note that if the ultimate goal of medical practices is production of morally acceptable medical services, achieving this goal is dependent on several factors including medical team members' internal (personal) morality, institutional policies and high level policies of regional and national health system and even, moral values of the society. Moreover, it is not only the physician who has a critical role in forming an ethical health system, but also patients and their families have important responsibilities, which should be fulfilled. Finally in modern medicine, the role of medical institutions, which serve as intermediate organizations for connecting patients and physicians, in providing morally acceptable medical care or performing acceptable medical research should not be forgotten. In this regard, noticing the following issues seems to be of high importance:

1-Although physicians and other medical team members' rights should not be forgotten, the "Art of Medicine" from the time of Hippocrates has been "Patient
Oriented". In other words, the best interest or benefit of patients is the substantial value of medical practice and research. In such context, today the issue of "Conflict of Interest" needs more scrutiny. This situation happens when there are competing interests other than patients' interests. Financial interests of the physicians in cases such as those having shares in Para-clinic institutions to which they refer their patients and having financial relationships with pharmaceutical companies, products of which they prescribe, are examples of "Conflict of Interest Situations". Such situations need to be seriously avoided by all medical professionals. In case that they cannot be avoided they need to be clearly declared [1]. 2- Performing standard medical practices based on the latest developments in the field of medicine is the first and also the most important step in providing moral medical service. Furthermore, all of the medical interventions are morally justified if they are compatible with accepted moral norms of medical ethics including, beneficence of medical interventions for patients' well- being, respect to human dignity and autonomy of patients in decision making and considering the principal of justice. Accordingly, respecting patients' religious-cultural values, treating them respectfully, politely with compassion and fairness, avoiding various types of racial, religious, cultural and sexual discrimination and emphasizing on the rights of vulnerable groups, especially pregnant women, widows, mentally retarded patients, refugees and immigrants and the disabled population should be seriously taken into consideration [2].

3- Respecting human's dignity and freedom in clinical settings requires that, before any medical intervention, the physicians need to be sure of patients' or surrogates' competency and capacity for receiving and understanding related medical information. Ambiguous cases should be referred to medical ethics committee of the hospital/clinic, to a consultant medical ethicist or official legal authorities. It is required to inform patients with all possible information about diagnosis and prognosis of their disease, various methods of treatments, their weakness and strength and possible and noticeable complications, in an understandable language to ensure that the patient has realized the information in 
order to provide a valid informed consent. It is suggested to obtain a separate written content for each important intervention. Therefore, obtaining a general consent at the time of admission is not enough $[3,4]$.

4- Respecting the patients' right to privacy and confidentiality of their medical information in a way that only patients, those people who are authorized by them and their medical team members are permitted to access such information, is necessary during all steps of any medical intervention and research. This rule of confidentiality involves situations in which there is a fear of the same medical problems such as probability of familial breast cancer for other people. In such situations it is recommended for physicians to encourage the patients to disclose their medical secrets to others who are in danger, otherwise clinical ethics committees would be asked to help $[4,5]$.

5- According to the principle of veracity and the patients' right to be informed of their medical situation, breaking the bad news including the diagnosis of breast cancer, recurrence or metastasis is morally recommended [6]. Moreover, the way such news will be delivered should be adjusted by the patients' attending physicians, based on patients' personal and social status. It is usually accepted that delivering such news should be step by step, in a private and calm environment and during a meeting session in which the physician has enough time to communicate with the patients/families, based on a confirmed and verified diagnosis [7].

6- At the end of the life period of patients whose diseases are in an irreversible status and their death is imminent, according to the physician's medical evaluation, all of the medical interventions should be performed in order to reduce the patients' suffering, enhancing their comfort and responding to their mental, spirited and emotional needs. Medically futile treatments could be forgone (withheld or withdrawn) after informing the patients/surrogates, mainly because the scope of respecting the patients' decisions is limited to those medically approved or accepted beneficial choices [8]. Forgoing (withholding or withdrawing) life-sustaining treatments should be decided by consultation with clinical ethics committees and also after obtaining informed consent from the patients/surrogates. The attending physician can ask and document competent patients' points of view about probable future interventions for the times of patients' lack of capacity and competency for decision making $[8,9]$.
7- It is required for the physicians and other responsible team members to educate patients and families with necessary information and to set future medical plans for continuation of diagnostic, curative or even palliative cares, and also for referring patients for more investigations, interventions and rehabilitative efforts. In all situations where the responsible physician cannot be sure about the moral acceptance of a medical intervention or when they face sensitive and problematic situations such as prophylactic mastectomy or aborting a pregnant woman's fetus, it is required to refer the case to clinical ethics committee of the medical institution. In absence of such committee performing an ethical consultation with a medical ethicist or obtaining the viewpoint of at least two other medical practitioners could be helpful [10].

\section{REFERENCES}

1. Sacristan JA. Patient-centered medicine and patient-oriented research: improving health outcomes for individual patients. BMC Med Inform Decis Mak. 2013;13:6. DOI: 10.1186/1472 6947-13-6 PMID: 23294526

2. Goldenberg MJ. On evidence and evidence-based medicine: lessons from the philosophy of science. Soc Sci Med. 2006;62(11):2621-32.DOI: 10.1016/j.socscimed.2005.11.031 PMID: 16384628

3. Beach MC, Sugarman J, Johnson RL, Arbelaez JJ, Duggan PS, Cooper LA. Do patients treated with dignity report higher satisfaction, adherence, and receipt of preventive care? Ann Fam Med. 2005;3(4):331-8. DOI: 10.1370/afm.328 PMID: 16046566

4. Woogara J. Patients' rights to privacy and dignity in the NHS. Nurs Stand. 2005;19(18):33-7. DOI: 10.7748/ ns2005.01.19.18.33.c3783 PMID: 15683053

5. Moskop JC, Marco CA, Larkin GL, Geiderman JM, Derse AR. From Hippocrates to HIPAA: privacy and confidentiality in emergency medicine--Part I: conceptual, moral, and legal foundations. Ann Emerg Med. 2005;45(1):53-9. DOI: 10.1016/j. annemergmed.2004.08.008 PMID: 15635311

6. Faden RR, Beauchamp TL, Kass NE. Informed consent for comparative effectiveness trials. N Engl J Med. 2014;370(20):195960. DOI: $10.1056 /$ NEJMc1403310 PMID: 24827051

7. Martins RG, Carvalho IP. Breaking bad news: patients' preferences and health locus of control. Patient Educ Couns 2013;92(1):67-73. DOI: 10.1016/j.pec.2013.03.001 PMID: 23523195

8. Foo WT, Zheng Y, Kwee AK, Yang GM, Krishna L. Factors considered in end-of-life care decision making by health care professionals. Am J Hosp Palliat Care. 2013;30(4):354-8. DOI: 10.1177/1049909112453193 PMID: 22802533

9. Marc Ho ZJ, Krishna LK, Goh C, Alethea Yee CP. The physician-patient relationship in treatment decision making at the end of life: a pilot study of cancer patients in a Southeast Asian society. Palliat Support Care. 2013;11(1):13-9. DOI: 10.1017/ S1478951512000429 PMID: 22804832

10. Shuman AG, Montas SM, Barnosky AR, Smith LB, Fins JJ McCabe MS. Clinical ethics consultation in oncology. J Oncol Pract. 2013;9(5):240-5. DOI: 10.1200/JOP.2013.000901 PMID: 23943899 